\title{
MEDICALIZAÇÃO E A ATUAÇÃO FONOAUDIOLÓGICA FRENTE À QUEIXA ESCOLAR
}

\author{
MEDICALIZACIÓNEN YACTUACIÓN FONOAUDIOLÓGICA DELANTE DE LA \\ QUEJA ESCOLAR
}

\author{
MEDICALIZATIONANDSPEECH THERAPY PERFORMANCE ADDRESSING \\ SCHOOL COMPLAINT
}

Bárbara Aparecido BOTELHO ${ }^{1}$

Elaine Cristina de OLIVEIRA ${ }^{2}$

RESUMO: A queixa escolar é, em geral, caracterizada como experiências de fracasso no contexto educacional que se manifestam pela expressão de sofrimento e envolve atores como a criança, a família e a escola. São poucos os estudos que buscam compreender o processo de produção das queixas escolares e a relação deste processo com a medicalização. Deste modo, este estudo teve como objetivo analisar relatos de fonoaudiólogos sobre a sua atuação com crianças com queixas escolares e identificar o quanto essa atuação se aproxima ou se distancia de práticas que contribuem para o processo de medicalização da educação. Trata-se de estudo qualitativo e transversal, fundamentado em perspectiva teórico-metodológica sócio-histórica. Participaram seis fonoaudiólogas que atendiam crianças com queixas escolares na rede pública e privada da região de Salvador/BA. A coleta de dados foi realizada por meio de entrevistas semiestruturadas que, após transcritas, foram categorizadas e analisadas tendo por base os objetivos propostos e referencial teórico baseado em estudos sobre queixa escolar, fracasso escolar, fonoaudiologia e medicalização. Conceitos sobre enunciado e dialogia também foram importantes para a seleção e análise dos dados. A análise dos enunciados das entrevistas tornou possível observar que semelhanças, diferenças e contradições atravessaram as narrativas sobre as diversas práticas clínicas relacionadas às queixas escolares. Os enunciados das fonoaudiólogas foram marcados por práticas ora medicalizantes, ora não medicalizantes, e apontam que ainda há um longo caminho na tentativa de romper com a perspectiva ideológica da clínica biomédica e medicalizante na atuação com a queixa escolar.

PALAVRAS-CHAVE: Queixa escolar. Educação. Medicalização. Fonoaudiologia.

RESUMEN: La queja escolar, en general, se caracteriza por experiencias de fracaso en el contexto educativo que se manifiestan por la expresión de sufrimiento e involucran a actores como el niño, la familia y la escuela. Hay pocos estudios que buscan comprender el proceso de producción de quejas escolares y la relación entre este proceso y la medicalización. Por lo tanto, este estudio tuvo como objetivo analizar informes de terapeutas del habla sobre su trabajo con niños con quejas escolares e identificar cuánto este trabajo está cerca o lejos de

${ }^{1}$ Universidade Federal da Bahia (UFBA), Salvador - BA - Brasil. Doutoranda no Programa de Pós-graduação em Educação. ORCID: https://orcid.org/0000-0003-0690-4628. E-mail: barbarabotelho.fono@hotmail.com ${ }^{2}$ Universidade Federal da Bahia (UFBA), Salvador - BA - Brasil. Professora do Departamento de Fonoaudiologia. Doutorado em Linguística (UNICAMP). ORCID: https://orcid.org/0000-0001-8393-4025. E-mail: elaine.oliveira@ufba.br 
las prácticas que contribuyen al proceso de medicalización de la educación. Este es un estudio cualitativo y transversal, basado en una perspectiva teórico-metodológica sociohistórica. Participaron seis terapeutas del habla que atendieron a niños con quejas escolares en las escuelas públicas y privadas de la región de Salvador / BA. La recopilación de datos se realizó a través de entrevistas semiestructuradas que, después de ser transcritas, se clasificaron y analizaron en función de los objetivos propuestos y el marco teórico basado en estudios sobre quejas escolares, fracaso escolar, logopedia y medicalización. Los conceptos sobre la expresión y el diálogo también fueron importantes para la selección y el análisis de los datos. El análisis de las declaraciones de la entrevista permitió observar que las similitudes, diferencias y contradicciones cruzaban las narrativas sobre las diferentes prácticas clínicas relacionadas con las quejas escolares. Las declaraciones de los terapeutas del habla se caracterizaron por prácticas que a veces son medicalizadas, a veces no medicalizadas, y señalan que aún queda un largo camino por recorrer para tratar de romper con la perspectiva ideológica de la clínica biomédica y medicalizadora en el tratamiento de las quejas escolares.

PALABRAS CLAVE: Queja escolar. Educación. Medicalización. Fonoaudiología.

ABSTRACT: School complaints are generally characterized as experiences of failure in the educational context that manifest themselves in the expression of suffering and involve actors such as the child, the family and the school. Few studies seek to understand the process of production of school complaints and the relationship between this process and medicalization. Thus, this study aimed to analyze reports from speech therapists about their work with children with school complaints and identify how much this work approaches or distances itself from practices that contribute to the process of medicalization of education. It is a qualitative and transversal study, based on a socio-historical theoretical-methodological perspective. Six speech therapists who attended children with school complaints in the public and private networks in the region of Salvador/BA participated. Data were collected through semistructured interviews that, after transcribed, were categorized and analyzed based on the proposed objectives and theoretical reference based on studies on school complaints, school failure, speech therapy and medicalization. Concepts about enunciation and dialogue were also important for the selection and analysis of data. The analysis of the interview statements made it possible to observe that similarities, differences and contradictions crossed the narratives about the various clinical practices related to school complaints. The statements of the speech therapists were marked by practices that were sometimes medicalizing, sometimes not medicalizing, and point out that there is still a long way to go in the attempt to break with the ideological perspective of the biomedical and medicalizing clinic in the performance with the school complaint.

KEYWORDS: School complaint.Speech-language therapy. Medicalization. Education.

\section{Introdução}

A criança que vivencia uma história de inadaptação ou dificuldade escolar é, em alguns casos, levada pela família ou responsáveis aos postos de saúde, clínicas-escolas, centro especializados de atendimento ou clínicas particulares com a chamada 'queixa escolar' (MACHADO, 1997), caracterizada, em alguns estudos (RODRIGUES; CAMPOS; 
FERNANDES, 2012; CAVALCANTI; AQUINO, 2018), principalmente por dificuldades comportamentais e/ou de aprendizagem. Diversos profissionais como fonoaudiólogos, psicólogos, psicopedagogos, médicos (especialmente os neurologistas) atuam com a queixa escolar, no entanto, poucos se preocupam com a complexidade de fatores - culturais, históricosociais, econômicos, políticos e biológicos - que determinam sua produção.

A Psicologia é a profissão precursora no debate sobre o tema da queixa escolar numa perspectiva histórico-crítica, especialmente nas áreas da Psicologia Escolar e Educacional. Os estudos de Maria Helena Sousa Patto sobre a produção do fracasso escolar, na década de 1980, foram importantes para que a Psicologia pudesse se afastar da perspectiva biologizante e medicalizante (PATTO, 1985; 1988). A emergência desses estudos não significou, até os dias atuais, unanimidade ou homogeneidade na área. Apesar da Psicologia crítica ter ampliado os estudos acerca da queixa e do fracasso escolar (ANGELUCCI, 2007; VIÉGAS, 2016; FARIA; INSFRAN, 2018; PATTO, 2015), nos últimos anos, ainda temos um número grande de psicólogos inseridos numa clínica medicalizante.

Assim como a Psicologia, ao longo da sua história, a Fonoaudiologia também foi construindo caminhos diversos. Em um desses caminhos, sustentada nas raízes biomédicas e nos ideais corretivos que deram início às suas práticas, como historiciza Berberian (1995), a fonoaudiologia produziu (e ainda produz) uma clínica que podemos chamar de medicalizante. É essa clínica que acolhe as queixas escolares e reproduz os estigmas sociais sobre o processo educacional e sobre o fracasso escolar. Atribui diagnósticos baseados no olhar sobre o corpo e passa a justificar o não aprender devido a patologias como déficits de processamento auditivo, visual e fonológico, por exemplo, desconsiderando a singularidade do sujeito, suas referências sociais e culturais e o próprio processo de aquisição da leitura e escrita que ocorre de forma singular e histórica (OLIVEIRA; TEIXEIRA; SANTOS, 2014). Esses rótulos geram implicações que vão muito além do espaço clínico e acompanham o sujeito por outras esferas da sua vida, deixando marcas importantes (SIGNOR; BERBERIAN; SANTANA, 2016).

Na contramão da clínica medicalizante, vem se construindo uma clínica desvencilhada da preocupação em categorizar e rotular patologias da linguagem, uma clínica pautada em uma visão discursiva da linguagem e numa concepção de sujeito singular e histórico (SANTANA, 2001; GUARINELLO et al., 2008; BARROS, 2012).

Ressalta-se que, neste estudo, compreende-se o termo medicalização de acordo com a Carta do IV Seminário Internacional 'A educação medicalizada: desver o mundo, perturbar os sentidos', publicada pelo Fórum sobre Medicalização da Educação e da Sociedade, em 2015: 
Medicalização envolve um tipo de racionalidade determinista que desconsidera a complexidade da vida humana, reduzindo-a a questões de cunho individual, seja em seu aspecto orgânico, seja em seu aspecto psíquico, seja em uma leitura restrita e naturalizada dos aspectos sociais. Nessa concepção, características comportamentais são tomadas apenas a partir da perspectiva do indivíduo isolado, que passaria a ser o único responsável por sua inadaptação às normas e padrões sociais dominantes. A medicalização é terreno fértil para os fenômenos da patologização, da psiquiatrização, da psicologização e da criminalização das diferenças e da pobreza (FÓRUM, 2015, p. 1, op. cit. OLIVEIRA; HARAYAMA; VIÉGAS, 2016, p. 102).

Salienta-se que medicalização e patologização não são sinônimos. Patologização envolve necessariamente uma doença, e o processo de medicalização, nem sempre. São processes relacionados, visto que a patologização está sempre implicada num processo mais amplo de medicalização (OLIVEIRA, HARAYAMA \& VIÉGAS, 2016).

Partindo do fato de que as bases teóricas que sustentam as práticas fonoaudiológicas não são homogêneas, o presente artigo teve como objetivo analisar relatos de fonoaudiólogos sobre a sua atuação com crianças com queixas escolares e, assim, identificar o quanto essa atuação se aproxima ou se distancia de práticas que contribuem para o processo de medicalização da educação.

\section{Aspectos metodológicos}

Esta pesquisa utilizou abordagem metodológica qualitativa, de caráter transversal, fundamentando-se em uma perspectiva sócio-histórica, com o intuito de superar os reducionismos das concepções empiristas e idealistas (FREITAS, 2002). De acordo com Freitas (2002), o trabalho com a pesquisa qualitativa numa abordagem sócio-histórica “[...] consiste pois, numa preocupação de compreender os eventos investigados, descrevendo-os e procurando as suas possíveis relações, integrando o individual com o social"' (p. 28). A presente pesquisa seguiu as normas estabelecidas pela resolução 466/12 e foi submetida ao Comitê de Ética em Pesquisa do Instituto de Ciências da Saúde (ICS), da Universidade Federal da Bahia, e aprovada sob o número 2.128.468.

Para a realização desta pesquisa optou-se por selecionar fonoaudiólogos que atendessem sujeitos com queixas de dificuldades escolares (leitura, escrita, comportamento, desatenção, entre outras) na cidade de Salvador (BA), em clínicas de serviços públicos e/ou privados. Como critério de inclusão, esses profissionais deveriam ter no mínimo dois (02) anos de experiência profissional no atendimento de crianças com queixa escolar. 
Os profissionais foram selecionados seguindo o critério da técnica snowball, na qual cada participante indicaria outro que atendesse ao critério de inclusão (FLICK, 2009). O primeiro participante foi selecionado a partir do ciclo de relação profissional de uma das pesquisadoras, que realizava um curso de pós-graduação latto sensu na área da linguagem durante o período de início deste estudo e convivia com fonoaudiólogas com diferentes formações e que atuavam clinicamente em diferentes instituições.

Desse modo, participaram deste estudo um total de seis (06) fonoaudiólogas com idades entre 26 anos e 31 anos, identificadas neste artigo com a letra 'P', seguida dos números de 1 a 6. No Quadro 1, pode-se observar informações mais detalhadas de cada participante no que se refere à formação e ao setor de trabalho:

Quadro 1 - Perfil das Participantes

\begin{tabular}{|l|c|c|c|c|c|}
\hline & IDADE & GRADUAÇÃO & $\begin{array}{c}\text { TEMPO } \\
\text { ATUAÇÃO } \\
\text { PROFISSIONAL }\end{array}$ & $\begin{array}{c}\text { SERVIÇO } \\
\text { PÚLLICO/PRIVADO } \\
\text { DE ATUAÇÃO }\end{array}$ & $\begin{array}{c}\text { AUTRAS } \\
\text { FORMAÇÓES }\end{array}$ \\
\hline P1 & 27 anos & Pública & 5 anos & Público & $\begin{array}{c}\text { Especialização } \\
\text { Linguagem } \\
\text { Mestranda em Políticas } \\
\text { Públicas }\end{array}$ \\
\hline P2 & 29 anos & Privada & 9 anos & Privado & Não possui \\
\hline P3 & 28 anos & Pública & 5 anos & Privado & $\begin{array}{c}\text { Especialização em } \\
\text { Linguagem e } \\
\text { Motricidade Orofacial }\end{array}$ \\
\hline P4 & 31 anos & Pública & 3 anos & Privado & $\begin{array}{c}\text { Especialização em } \\
\text { Linguagem }\end{array}$ \\
\hline P5 & 26 anos & Pública & 4 anos & Privado & $\begin{array}{c}\text { Especialização em } \\
\text { Linguagem }\end{array}$ \\
\hline P6 & 31 anos & Pública & 9 anos & Público e Privado & $\begin{array}{c}\text { Especialização em } \\
\text { Linguagem } \\
\text { Mestrado e Doutorado } \\
\text { em Educação }\end{array}$ \\
\hline
\end{tabular}

Fonte: Acervo da pesquisa

Como estratégia para coleta de dados foi utilizada uma entrevista semiestruturada que abordava os seguintes temas: atuação de profissional com crianças com queixas escolares, formação profissional e sua relação com atores importantes no processo de escolarização (professores, diretores, coordenadores pedagógicos, por exemplo). As entrevistas foram realizadas em dia, horário e local estipulados pelo pesquisador e entrevistado, levando em consideração um ambiente de fácil acesso e conforto para ambos. As entrevistas foram gravadas em áudio e tiveram uma média de duração de trinta (30) minutos cada.

Após a coleta, as informações obtidas foram transcritas, organizadas, selecionadas e categorizadas, tendo por base os objetivos propostos e referencial teórico baseado em estudos 
sobre queixa escolar, fracasso escolar, fonoaudiologia e medicalização. Na seleção e análise dos dados, os conceitos de enunciado e dialogia, de Bakhtin (2003), também foram importantes. Os enunciados analisados, concretos e únicos, proferidos pelas participantes desta pesquisa, numa esfera da atividade humana (a entrevista), produzidos num contexto sócio-ideológico (BAKHTIN, 2003), foram analisados tanto do ponto de vista do conteúdo ideológico, quanto das condições de produção.

A leitura inicial das entrevistas possibilitou que os dados fossem organizados em duas grandes categorias de atuação com a queixa escolar: o momento da avaliação e as propostas terapêuticas decorrentes do processo avaliativo. A partir daí, foram organizados núcleos de sentidos relacionados às categorias mencionadas, criando subcategorias sobre os posicionamentos de cada entrevistado que nos possibilitaram analisar as diferenças ou proximidades de posicionamentos entre os entrevistados ou, ainda, as possíveis contradições de posicionamentos dentro de uma mesma entrevista.

\section{Resultados e discussão}

Após a leitura do material selecionado para análise, alguns pontos relevantes foram observados nos enunciados das fonoaudiólogas referentes à atuação dessas profissionais com a queixa escolar.

Buscou-se, de forma cuidadosa e atenta, trazer o olhar das entrevistadas sobre suas práticas terapêuticas relacionadas à queixa escolar, mais especificamente, à sua atuação com a criança, a família e a escola. Buscou-se, ainda, identificar o quanto essa atuação se aproximava ou se distanciava de práticas que contribuíam para o processo de medicalização da educação. Dois aspectos das práticas terapêuticas foram destacados: a avaliação e a terapia.

\section{Sobre o processo de avaliação}

É no processo avaliativo que se iniciam as relações entre terapeuta, criança e família, tendo como ponto de partida a queixa pregressa que promoveu esse encontro. Como em qualquer outra prática (clínica ou não, avaliativa ou não), esse encontro pode ser trilhado por caminhos medicalizantes ou não medicalizantes (GENTIL, 2016). A partir dos enunciados abaixo, é possível constatar que a avaliação é uma prática citada por quase todas as entrevistadas, trilhando diferentes caminhos: 
[..] o acolhimento que é um momento que a gente faz uma avaliação inicial, já tem o momento de escuta qualificada antes dele entrar em terapia com o paciente. (P1)

A gente recebe a criança, faz a avaliação... eu faço algumas avaliações, principalmente avaliações neuro, relacionadas ao desenvolvimento e tal vê quais são as demandas dentro da Fonoaudiologia que ela tá apresentando... alterações de Linguagem, o começo da leitura e escrita... então, assim, tá começando a desenvolver essa parte da leitura e escrita né? Como é que tá essa coerência, essa coesão? Como é que tá essa organização grafema, fonema? Hoje, aqui na clínica, a gente trabalha com avaliação global. O que é que a gente faz... a gente recebe a criança, passa por todos os profissionais e a partir dai a gente define se é só pra psicólogo, se é só pra fono. $(\mathrm{P} 2)$

Então, eu normalmente começo na escuta, ouvindo muito o que é que essa família traz, quais são as características que traz pra essa criança pra em seguida, eu conseguir fazer paralelos e explicações de quantas potencialidades eles não estão conseguindo enxergar, de quantos defeitos eles veem muito mais do que as características do não aprender, do comportamento, enfim... Então, primeiro eu escuto o que eles estão falando e dentro da terapia eu converso um pouco mais com a criança sozinha, vou inserindo os pais dentro desse... da terapia, pra que eu consiga tá mostrando assim "olha pra isso daqui que coisa linda que ele fez! Ele fez sozinho! (P3)

Depois do meu processo avaliativo de que eu pensei tudo que... né? Eu fechei a avaliação, eu vou à escola. (P4)

Eu atuo, em primeiro lugar, acolhendo essa queixa, acolhendo a demanda do sujeito, da família, da escola e buscando ressignificar essa relação de sofrimento do sujeito com a escrita ou com o processo educacional. (P6)

Nota-se, nos enunciados acima, que as entrevistadas P1, P3 e P6 descrevem sua prática avaliativa como um instante de escuta e acolhimento, tanto com a família quanto com o paciente, sendo o momento crucial para compreender melhor a queixa e não para a identificação de demanda estritamente fonoaudiológica, como apontado na fala de $\mathrm{P} 1$ : “... são crianças que às vezes já estão em tão sofrimento naquela escola que pra família é um alívio escutar que pode ser uma outra questão né?’. Ou seja, a escuta qualificada e acolhedora rompe com os estereótipos marcados na queixa e possibilita novos significados e caminhos para a criança e sua família frente ao processo escolar, como pode ser observado também nos enunciados de P3 e P6 elencados acima.

Por outro lado, pode-se observar, na fala da entrevistada $\mathrm{P} 2$, um processo avaliativo mais voltado à investigação de sinais e sintomas que caracterizam uma demanda fonoaudiológica (dificuldades na escrita, voz, motricidade orofacial, audição) e que podem estar associados ao processo de escolarização. Em um trecho da fala de P2, é possível observar essa prática: "Faço algumas avaliações, principalmente avaliações neuro, relacionadas ao desenvolvimento e tal [...] a gente recebe a criança faz a avaliação, vê quais são as demandas 
dentro da Fonoaudiologia que ela tá apresentando... vê se é só demanda, se ela só faz fono". A avaliação voltada apenas para identificação de sinais e sintomas é resultado das raízes biomédicas ainda impregnadas na Fonoaudiologia, em que o sujeito se torna apenas um corpo que é mapeado para identificação de características que justifiquem a atuação terapêutica (GENTIL, 2016). A entrevistada P4 menciona que realiza avaliação, mas não fornece nenhuma informação mais detalhada a respeito. Já P5 não menciona o processo de avaliação em nenhum momento da entrevista.

Outro destaque importante relacionado à avaliação diz respeito às dificuldades mencionadas por P3. A entrevistada relata que a família já chega no consultório solicitando uma avaliação específica, de um sintoma ou doença específica, usando um teste específico. P3 fala sobre sua dificuldade de lidar com essa postura da família:

Ela chegou pra mim perguntando já como que era a avaliação do DPAC, 'como que é essa avaliação? Você faz essa avaliação?' eu falei 'oh, quem encaminhou? Como foi isso? O que é que ela tem? Como você está se sentindo?', "não, assim oh, minha filha tem alguma coisa, eu tô buscando por isso né? Então, eu quero a avaliação do DPAC!', eu falei 'ah, você já sabe como é a avaliação do DPAC? Vamos explicar como é a avaliação do DPAC', expliquei tudo! (P3)

Para Amaral, Carvalho e Collela-Santos (2020), o DPAC (Distúrbio do Processamento Auditivo Central) "é definido como um déficit no processamento neural dos estímulos auditivos e pode coexistir ou estar associado a alterações do desenvolvimento de linguagem e/ou quadros neurológicos" (p. 2). Entre as alterações de linguagem mais frequentes, mencionadas como decorrentes do DPAC, estão as dificuldades de leitura e escrita e o Transtorno do Déficit de Atenção e Hiperatividade (TDAH), considerado uma comorbidade. Oliveira, Harayama e Viégas (2016) destacam que a procura pela realização do diagnóstico do DPAC em crianças em idade escolar tem aumentado consideravelmente, e a confirmação do diagnóstico "tem servido como espécie de ópio que inebria a reflexão sobre os complexos processos envolvidos no fracasso escolar da criança diagnosticada" (p. 114). Os autores ressaltam, ainda, que "tem chamado a atenção que famílias, escolas e mesmo profissionais de saúde têm reivindicado o diagnóstico do DPAC e de outros transtornos (como TDAH e dislexia), afirmando-o como um direito da criança” (p. 114). A família cobra da terapeuta um procedimento específico, algumas vezes porque é orientada pelo médico ou outro profissional, mas, também, porque é atravessada por uma ideologia medicalizante - da qual tem se tornado muito difícil escapar - e acredita que aquele diagnóstico específico pode ser tanto a cura quanto o acesso a uma educação de qualidade. 
Além disso, P3 menciona como o sistema privado lida com diferentes abordagens metodológicas. Segue o comentário de P3:

Expliquei o que que era diferente da minha abordagem, como era minha abordagem e isso eu não consigo numa sessão de plano. Então, extrapola essa relação privada que a gente acaba caindo. Enfim, nesse caso foi um caso assim, foi um dos mais complicados assim, porque era uma familia que deseja uma outra coisa. Então, pra conseguir trazer outra informação é muito dificill! Se ela já vai com um pensamento formado, algum diagnóstico na avaliação objetiva, o quê que aquele neuro disse, o que aquele profissional ou outro falou, o que ela leu na internet... então, quando eles já vão com essa ideia sedimentada é muito complicado a gente conseguir mostrar um outro ponto de vista, mostrar uma outra abordagem. (P3)

O sistema privado de saúde opera não só sobre o processo diagnóstico, mas, também, interfere nas práticas fonoaudiológicas de modo geral, como apontado por P3. O profissional se vê limitado a seguir padrões de atuação do sistema privado de saúde, o qual, muitas vezes, restringe a atuação do profissional de saúde a regras e protocolos centrados no modelo hegemônico. Caso o fonoaudiólogo busque atuar de forma diferente, o sistema o tensiona para que ele não consiga, como ressalta $\mathrm{P} 3$. Tanto o sistema público quanto o privado de saúde podem impor limites em relação às escolhas e às possibilidades de atuação profissional com a queixa escolar, no entanto, vínculos precários, nos quais “os riscos empregatícios são assumidos principalmente pelos trabalhadores e não pelos seus empregadores ou pelo governo" (EBERHARDT; CARVALHO; MUROFUSE, 2015, p. 19), podem reduzir as possibilidades de enfrentamento da perspectiva hegemônica. Resistir e existir dentro desses sistemas, num modelo que propõe desmedicalizar a saúde, a educação e a vida não têm sido tarefa muito fácil.

O sistema público, apesar de todas as limitações estruturais, na gestão e nas condições de trabalho, propõe olhares e vivências que podem ir além das amarras do sistema capitalista dos serviços privados em saúde, colocando o profissional em situações que propiciam um atendimento clínico mais amplo. Infelizmente, a realidade do fonoaudiólogo no Sistema Único de Saúde ainda é tímida, sendo a região Nordeste a região com menor oferta e expansão da profissão no SUS (SOUSA et al., 2017).

\section{Sobre o processo terapêutico}

No que se refere ao enfoque das práticas terapêuticas realizadas com as queixas escolares, observou-se que tais práticas são construídas a partir dos dados obtidos na avaliação fonoaudiológica, e dois pontos foram ressaltados na atuação de todas as entrevistadas: o trabalho com a família e a escola. 
Quanto ao trabalho realizado com a família, mesmo sendo considerada um ator importante no processo terapêutico, observou-se práticas distintas. As entrevistadas P2, P3, P4 e P5 priorizaram práticas mais verticalizadas, unidirecionais e, por vezes, culpabilizantes, porque apontavam a família como responsável pelo sucesso ou insucesso terapêutico. Seguem alguns trechos das entrevistas:

A família tem orientação. Eu faço a família entender o processo, o que está sendo feito, o que está sendo trabalhado e o que é que ela pode observar na criança, no outro contexto, na casa, nas atividades da escola, nas reuniões da família... ela também tá levando toda a terapia, claro que de uma forma mais tranquila não tão terapêutica, não tão profissional mas dar continuidade aquilo que a gente já tá fazendo em clínica. Eu tento fazer reunião com os pais pelo menos a cada mês. (P2)

Então, com os pais é o essencial, não tem como ter terapia com criança sem incluir os pais, ainda mais pra isso, ainda mais pra leitura e escrita" o que é que eu vejo ultimamente, mais assim... os pais que são céticos, que não acreditam naquilo que eu tô fazendo, porque é muita brincadeira e eles querem atividade ou então com cobranças "cadê? Ele não tá escrevendo... agora acabou, a dificuldade tá aí, a professora tá cobrando, todo mundo tá cobrando! Me dê resultado!" A gente precisa de construção e parceria. E aí, muitos pais, muitos, muitos eu consigo conscientizar, assim, trazer a minha abordagem, como é que a gente faz pra inserir, com os pais eu preciso dizer vinte vezes a mesma coisa pra gente conseguir ter essa disponibilidade de ter mudanças no seu dia a dia, que são tão pequenas...minha interpretação com os pais é de ter muita paciência, precisa ter paciência porque, de fato, a gente precisa repetir um pouco as coisas. ( $\mathrm{P} 3)$

Com a família o tempo todo! Desde o início até o final. Então tem mães que eu não tiro da terapia nos três, quatro primeiros meses de terapia e ela fica dentro da sala o tempo todo. Já tem outras que depende muito da gravidade da situação. Você percebe que a mãe responde aos estímulos que a gente pede somente naquele finalzinho de terapia e eu tiro ela e no finalzinho a gente chama. Se for uma mãe que é muito resistente, que você percebe que você tá falando e ela não tá entendendo, ou ela tá falando e fazendo de forma diferente, ela não tá conseguindo compreender, ela fica em terapia para observar os momentos que a criança tá fazendo, como a gente tá atuando pra ela tentar reproduzir isso em casa da melhor forma possivel. (P4)

O sucesso tá completamente ligado a isso e a família em qualquer situação, que é ela que é a interessada né? Que é que vai promover realmente as mudanças que a gente sugere e... mostra o que é melhor para aquela criança. Se ela não fizer não vai adiantar né? (P5)

Nota-se, nos enunciados de P2, P3, P4 e P5, que a atuação com a família prioriza uma prática bastante comum denominada de 'orientação', na qual o profissional, detentor do saber, instrui a família sobre o que fazer (e como) para que a criança melhore. Nessa prática, observase a presença de uma clínica tradicional biomédica, prescritiva, verticalizada e culpabilizante. Nesse modelo de atuação, as diferentes estruturas e arranjos familiares, as condições 
socioeconômicas, o papel do cuidador - especialmente da mãe (em geral, atravessado por um modelo patriarcal que a sobrecarrega) - e as relações culturais e afetivas não são consideradas, por isso, esse modelo tem por base uma atuação reducionista e medicalizante. Numa clínica de caráter medicalizante, questões como estruturação familiar, relações familiares, baixo poder aquisitivo com condições precárias de vida são relacionadas ao aprendizado da criança (FERRIANI \& IOSSI, 1998) e servem apenas para justificar o não aprender. Já os enunciados de P1 e P6 configuram-se numa outra perspectiva de atuação:

Todas as sessões têm esse momento de conversar com a família no final da sessão. Então, é bacana você mostrar para a mãe e para o familiar o outro lado da história também, das potencialidades da criança pra que a família enxergue. Porque às vezes a família só enxerga a dificuldade... até pelo discurso se você for analisar "olha não consegue, não faz. Ainda não consegue isso". Então mostrar o outro lado da moeda pra família também. (P1)

Então, acolho sim essa demanda e tento ir ressignificando e construindo um novo olhar junto com a familia, [...] sempre procuro conversar com as pessoas que fazem parte do processo educacional dessa criança, desse adolescente, pra juntos a gente construir uma nova perspectiva de relação desse sujeito com a linguagem. (P6)

Observa-se, nos enunciados das entrevistadas P1 e P6, práticas pautadas em relações mais horizontalizadas e dialógicas, uma atuação fonoaudiológica que busca compreender que a família é parte essencial no processo escolar da criança e que nela há dificuldades e potencialidades. Ressaltam a importância de uma escuta atenta que acolha angústias e vivências, uma escuta que possa ressignificar estigmas e estereótipos, capaz de encontrar de forma partilhada caminhos que levem ao enfrentamento da queixa de fracasso escolar.

Quanto ao trabalho realizado com a escola, todas as entrevistadas apontaram que a relação com a escola é muito importante para a atuação clínica, no entanto, é possível notar diferenças e contradições em relação ao modo como essa relação é construída.

A entrevistada P4, por exemplo, aponta que, após a avaliação fonoaudiológica da criança na clínica, sua atuação passar a ocorrer no espaço escolar para observação da escola e da criança:

Eu fechei a avaliação, eu vou a escola, sempre marco com a escola a primeira visita para observação. Então, a visita que eu vou tentar ficar lá na escola só observando o comportamento daquela criança na sua rotina de aula e de intervalo, de recreio com as outras crianças. (P4). 
Em seguida, P4 refere que retorna à escola para implantar as estratégias fonoaudiológicas junto ao professor e coordenador pedagógico e, também, com o objetivo de ouvir mais o professor e/ou o coordenador:

Eu retorno à escola para conversar com o professor e o coordenador pedagógico para ouvir a demanda dele e a partir disso a gente sentar e pensar em estratégias conjuntas, se assim for necessário porque tem crianças que precisam que o professor adeque as suas atividades pedagógicas a demanda da criança.

P4, nesse enunciado, assume uma postura que busca o diálogo e a construção conjunta de estratégias que podem ajudar a criança no processo escolar, afirma que é necessário que o professor "adeque as suas atividades pedagógicas à demanda da criança". Quando a pesquisadora pergunta sobre as dificuldades apresentadas por P4 na sua atuação com a queixa escolar, algumas contradições aparecem em sua narrativa:

Tem professores que são extremamente resistentes aquele trabalho. Já teve professor de me perguntar "vem cá, mas você vai fazer o meu trabalho pedagógico?" ou então de... eu dou muito o meu whatsapp, todo mundo tem meu whatsapp, mas ele não procura, ele não tem aquele retorno, ele não vai, apesar de você se colocar à disposição. Então se eu for dizer a você, metade, metade. Metade eu tenho tido uma boa aceitação e a outra metade infelizmente não. [...] A gente fica na maioria das vezes com a criança uma ou duas vezes na semana. O professor fica todos os dias da semana a depender se for um turno integral fica o tempo todo com a criança. E ai ele tem um papel privilegiado que é esse. Se a gente souber juntar e fazer uma parceria boa e interessante, aquele professor vai ser o multiplicador e vai ajudar aquela criança a potencializar o que a gente vem trabalhando em terapia. Então pra mim é de extrema importância. (P4).

Ao dizer que os professores são extremamente resistentes ao trabalho fonoaudiológico, nota-se uma culpabilização do professor pela dificuldade da fonoaudióloga em acessá-lo. A entrevistada P4 atribui essa 'resistência' ao desconhecimento do trabalho do fonoaudiólogo por parte do professor ou uma ameaça quanto à suposta possibilidade do fonoaudiólogo assumir o papel pedagógico do professor. O professor é culpabilizado por não aderir ao trabalho proposto e não dar retorno ou não entrar em contato com a profissional. P4 continua seu enunciado falando sobre a importância do professor, que tem o privilégio de ficar com a criança a semana toda e, por isso, poder ser um 'multiplicador', no sentido de potencializar o processo terapêutico. Gomes e Brito (2006) salientam o quanto os profissionais de educação têm sido exigidos para que ofereçam qualidade de ensino, dentro de um sistema cujos recursos materiais e humanos cada vez mais precarizados, os salários baixos e a sobrecarga de funções contribuem 
para um esgotamento físico e prejuízos à saúde. É preciso cuidado nas parcerias que realizamos com os professores para que nossas práticas não se tornem mais uma sobrecarga.

Algumas contradições também podem ser vistas nos enunciados de P5, quando essa entrevistada trata da sua relação com a escola e das dificuldades enfrentadas nesta relação:

\begin{abstract}
Mas pra escola fica uma consultoria, de como eu posso ajudar essa criança na sala. Então eu vou ajudar os professores a entender essa parte. Eu acho que beira consultoria e na verdade, ouvir qual é o real problema né? Qual é a real dificuldade da criança naquele âmbito. Eu acho que é mais ou menos por ai. (P5)

A dificuldade muito grande! Da escola, eu acho que é de colocar em prática o que a gente orienta por conta da dinâmica de sala né? É vinte alunos, três auxiliares, não dá pra dar atenção especial a uma criança, por exemplo, que não tem um diagnóstico médico... que é a maioria das nossas crianças né? Que vem pra diagnóstico fonoaudiológico. Inclusive eu passei por isso ontem. Então, assim, é difícil... eles encaram de forma diferente. Se tiver diagnóstico é muito melhor pra eles. Eles vão colocar no $20 \%$ do/da adaptação curricular né? Da da taxa de é... de crianças especiais, seja qual for o diagnóstico, não faz diferença. Pode ser uma TEA, pode ser um TDAH, mas vindo de um psiquiatra, por exemplo, eles já podem usar o diagnóstico como ferramenta para adaptar. (P5)
\end{abstract}

Observa-se, nos enunciados, que a entrevistada P5 compreende sua prática como uma consultoria. P5 relata, em vários momentos da entrevista, seu esforço para estar na escola com o intuito de compreender as dificuldades da criança nesse contexto. No entanto, seu olhar é medicalizante, por exemplo, quando se coloca numa posição assimétrica em relação ao professor (e à escola) que recebe suas orientações, partindo do pressuposto de que seu saber técnico é superior. Também é medicalizante quando foca sua prática no diagnóstico fonoaudiológico relacionado a uma doença e não no funcionamento da linguagem, bem como quando relaciona a nomeação de um diagnóstico ao acesso a uma educação de qualidade e inclusiva.

As fonoaudiólogas P1, P3 e P6, por outro lado, apontam para uma atuação na qual se preocupam com a parceria estabelecida com a escola e com a necessidade de repensar a postura dos fonoaudiólogos nessa relação, assim como se preocupam com a subjetividade do sujeito e com o sofrimento decorrente das experiências com a linguagem no ambiente escolar. $\mathrm{O}$ enunciado de P1 demonstra sua preocupação em construir parcerias com a escola e outros profissionais e repensar a postura da Fonoaudiologia nessa relação:

Essa articulação com outros profissionais é... em outras áreas já é importante quanto mais em leitura e escrita também. De como ir na escola, de saber qual é a postura que você vai adotar na escola também, porque você não vai 
interferir na conduta pedagógica, mas você pode ser um parceiro desse profissional. Então da gente repensar também a nossa postura nesses espaços, que às vezes, a nossa postura nesses espaços faz com que esses outros profissionais tenham um outro olhar sobre a gente né? (P1).

Já a entrevistada P3 aponta, em seu enunciado, as dificuldades de realizar visitas à escola devido à sua rotina de trabalho e a da própria escola. Também traz comentários relevantes sobre o objetivo da visita:

Então, normalmente não são feitas tantas visitas à escola quanto eu gostaria. Tanto a rotina da própria escola como a rotina da gente... se a gente pensa no atendimento ideal eu pensaria em uma presença muito maior dentro da escola. [...] Essa visita na escola que tem o objetivo tanto de ver como é que eles estão correlacionando, como é o material da escola, como é a avaliação, o que é que tá acontecendo lá dentro... e eu vejo se eles estão precisando de mais suporte, eu passo material também... e assim... sobre pedagogia, sobre o processo de alfabetização, sobre o tipo de base da escola, então se ela é construtivista... então, isso eu acho que falta pra gente esse conhecimento e eu não consigo também avaliar essa parte... não consigo me aproximar muito dessa temática sobre avaliação, sobre currículo. Eu gostaria muito mais de me aprofundar nessa área, nessa parte que envolve a escola, mas, ainda, eu fico numa parte um pouquinho mais restrita. (P3)

No enunciado de P3, vê-se que a proposta de atuação com a escola é também compreender o seu funcionamento, a rotina e a material didático-pedagógico. P3 aponta que tem dificuldade de construir, em sua rotina, uma relação com a escola e aponta que a rotina da escola também pode ser um complicador. Outro ponto relevante na fala de P3 é a sua inquietação com o conhecimento restrito da formação fonoaudiológica em relação aos conhecimentos de cunho educacional, sobre o currículo e avaliações. A entrevistada P6 segue numa direção mais dialógica e desmedicalizada e destaca que:

Acho importante que o fonoaudiólogo considere que uma história que chega marcada por uma queixa escolar, não é uma história que está isolada do contexto social como um todo né. A escola não é uma ilha na sociedade, ela tá imersa em uma sociedade desigual, em uma sociedade que prioriza uma determinada classe social, onde especialmente no nosso país, no nosso... na nossa região, no nosso estado, não são todos que tem as melhores condições de ter acesso a cultura, de ter acesso à educação. Então, o fonoaudiólogo precisa saber que o seu papel não é só considerar as questões de ordem biológica, mas considerar que esse sujeito está inserido em um contexto né, e esse contexto ele é social e é histórico. [...] Em geral, quando tem algum sujeito que chega à clínica com queixa escolar, eu sempre mantenho contato com a escola, sempre busco fazer reuniões com a coordenação pedagógica, com o professor, com o profissional de saúde que, de repente, tenha na escola e acompanha o caso. Então, é a forma que hoje eu encontro de ter acesso a escola é essa. 
Em seu enunciado, P6, ao definir a escola como parte da sociedade e determinada por aspectos sócio-históricos, também problematiza o papel do fonoaudiólogo e seu compromisso em compreender a queixa escolar como parte dessa construção histórica, de uma sociedade marcada pela desigualdade e pelos privilégios de classe - acrescentam-se, ainda, os privilégios de raça.

De modo geral, P1, P3 e P6 apresentaram práticas que podem ser compreendidas como sendo de caráter menos (ou não) medicalizantes, porque não culpabilizam o aprendiz, a família e/ou a escola pela queixa ou fracasso escolar, mas compreendem a complexidade sóciohistórica de cada um desses elementos. Desmedicalizantes porque não reduzem a criança ao seu diagnóstico (seja ele qual for) e apresentam práticas sustentadas num modelo interseccional e dialógico, cujo objetivo não é informar, orientar, mas transformar saberes existentes, construir de forma compartilhada e responsável práticas educativas emancipatórias que contribuam, de fato, para uma educação libertadora (FREIRE, 1996).

\section{Considerações finais}

A queixa escolar é uma das principais demandas na clínica fonoaudiológica. Marcada, principalmente, pelo não aprender, ela invade o espaço clínico e mobiliza o fonoaudiólogo a ir além das paredes do seu consultório e pensar no ambiente escolar e em todo o seu funcionamento, estrutura e atores envolvidos. Apesar da Fonoaudiologia ter germinado suas sementes no ambiente escolar, com apontado por BERBERIAN (1995), os ideais corretivos e do que é normal ou patológico no processo educacional, por vezes, ainda se configuram a partir de um olhar biologizante.

A análise dos enunciados das entrevistas tornou possível observar que semelhanças, diferenças e contradições atravessaram as narrativas sobre as diversas práticas clínicas relacionadas às queixas escolares.

O momento de avaliação foi apontado por algumas das participantes como o momento de identificação de sintomas/patologias voltadas à linguagem, evidenciando que as raízes biomédicas, sustentadas em práticas curativistas e reabilitadoras da comunicação humana, ainda orientam algumas práticas fonoaudiológicas. Por outro lado, outras entrevistadas reforçaram ser esse o momento de acolhimento das vivências escolares e de todo o processo de aprendizagem da criança e de sua família, estejam essas vivências vinculadas à difículdade da criança ou não. 
A análise dos enunciados apresentados neste artigo, marcados por práticas ora medicalizantes, ora não medicalizantes, aponta que ainda há um longo caminho a ser trilhado na tentativa de romper com a perspectiva ideológica da clínica biomédica. Muitos profissionais têm tentado romper com a lógica medicalizante e, por vezes, alguns são capturados pelas amarras do sistema que sufoca e aprisiona os sujeitos em sua forma biologizante de pensar a clínica, a educação e a vida.

Romper com a clínica hegemônica biomédica e medicalizante é uma tarefa árdua e trabalhosa, sendo necessária uma busca contínua pelo caminho que se deseja seguir. A trilha de um caminho desmedicalizante é composta por uma busca incessante de responsabilizar-se pela transformação da vida, sem rótulos e estigmas que aprisionam e sufocam todos os dias crianças e jovens brasileiros.

\section{REFERÊNCIAS}

ANGELUCCI, C. Por uma clínica da queixa escolar que não reproduza a lógica patologizante. In: SOUZA, B. P. (Org.). Orientação à queixa escolar. São Paulo: Casa do Psicólogo, 2007. p. 353-378.

AMARAL, M. I. R.; CARVALHO, N. G.; COLELLA-SANTOS, M. F. Programa online de triagem do processamento auditivo central em escolares (audBility): investigação inicial.

CoDAS, São Paulo, v. 31. n. 2, 2019.

BARROS, R. C. B. Estudo do campo de conhecimento fonoaudiológico e a clarificação do seu objeto científico. Rev. Línguas e Instrumentos Linguísticos, Ed. RG. Unicamp, 2012.

BAKHTIN, M. Os gêneros do discurso. In: BAKHTIN, M. (Org.). Estética da criação verbal. Trad. Paulo Bezerra. São Paulo: Martins Fontes, 2003. p. 261-306.

BERBERIAN, A. P. Fonoaudiologia e educação: um encontro histórico. 1. ed. São Paulo: Plexus, 1995.

CAVALCANTE, L. A.; AQUINO, F. S. B. Análise das queixas escolares considerando o processo de triagem: um estudo em clínicas escola de psicologia. Psicologia em Revista, Belo Horizonte, v. 24, n. 1, p. 158-174, jan. 2018.

EBERHARDT, L. D.; CARVALHO, M.; MUROFUSE, N. T. Vínculos de trabalho no setor saúde: o cenário da precarização na macrorregião Oeste do Paraná. Saúde em Debate, Rio de Janeiro, v. 39, n. 104, p. 18-29, mar. 2015.

FERRIANI, M. G.; IOSSI, M. A. Significado do fracasso escolar para os atores sociais que utilizam o programa de assistência primária de saúde escolar - PROASE no município de Ribeirão Preto. Rev. Latino-Am. Enfermagem, Ribeirão Preto, v. 6, n. 5, p. 35-44, dez. 1998. 
FLICK, U. Introdução à pesquisa qualitativa. 3. ed. Porto Alegre: Artmed, 2009.

FREIRE, P. Pedagogia da autonomia: saberes necessários à prática educativa. 2. ed. São Paulo: Paz e Terra, 1996. (Coleção Leitura)

FREITAS, M. T. A. A abordagem sócio-histórica como orientadora da pesquisa qualitativa. Cadernos de Pesquisa, São Paulo, n. 116, p. 21-39, jul. 2002.

GENTIL, M. A. O. Contribuição à crítica do trabalho da fonoaudiologia educacional à luz da concepção histórico-cultural da linguagem: Diante do crescente processo de medicalização e patologização da educação, que fazer? 2016. 260 f. Tese (Doutorado em Educação) - Universidade Federal da Bahia, Salvador, 2016.

GOMES, L.; BRITO, J. Desafios e possibilidades ao trabalho docente e à sua relação com a saúde. Estudos e Pesquisas em Psicologia, Rio de Janeiro, ano 6, n. 1, 2006. Disponível em: http://www.revispsi.uerj.br/v6n1/artigos/PDF/v6n1a05.pdf. Acesso em: 23 abr. 2020.

GUARINELLO, A. C.; MASSI, G.; BERBERIAN, A. P. A clínica fonoaudiológica e a linguagem escrita: estudo de caso. Revista CEFAC, São Paulo, v. 10, n. 1, p. 38-44, mar. 2008.

MACHADO, A. M. Avaliação e fracasso: a produção coletiva da queixa escolar. In: AQUINO, J. G. (Org.). Erro e fracasso na escola: alternativas e práticas. São Paulo: Summus, 1997. p. 73-79.

OLIVEIRA, E. C.; HARAYAMA, R. M.; VIÉGAS, L. S. Drogas e medicalização na escola: reflexões sobre um debate necessário. Revista Teias, v. 17, n. 45, p. 99-118, maio 2016.

OLIVEIRA, E.C.; TEIXEIRA, V.R.V.; SANTOS, J.G.R. Fonoaudiologia - Reflexões e Propostas de Superação do Discurso Medicalizante. In: MARCHESAN, I. Q. JUSTINO, H. TOMÉ, M. C. (Org) Tratado de Especialidades em Fonoaudiologia. São Paulo: Ed. Guanabara Koogan, 2014. p. 793-798.

PATTO, M. H. S. O papel social do psicólogo educacional. Revista Marco Eventos, São Paulo, Instituto de Ciências São Marcos, n. 1, p. 5-9, 1985.

PATTO, M. H. S. O fracasso escolar como objeto de estudo: anotações sobre as características de um discurso. Cadernos de Pesquisa (Fundação Carlos Chagas), São Paulo, p. $72-77,1988$.

PATTO, M.H.S. A produção do fracasso escolar: histórias de submissão e rebeldia. 4. ed. São Paulo: T.A. Queiroz, 2015.

RODRIGUES, M. C.; CAMPOS, A. P. S.; FERNANDES, I. A. Caracterização da queixa escolar no Centro de Psicologia Aplicada da Universidade Federal de Juiz de Fora. Estudos de Psicologia, Campinas, v. 29, n. 2, p. 241-252, jun. 2012.

SANTANA, A. P. A linguagem na clínica fonoaudiológica: implicações de uma abordagem discursiva. Distúrbios da Comunicação, São Paulo, v. 13, n. 1, p. 161-74, dez. 2001. 
SIGNOR, R. C. F.; BERBERIAN, A. P.; SANTANA, A. P. A medicalização da educação: implicações para a constituição do sujeito/aprendiz. Educação e Pesquisa, São Paulo, v. 43, n. 3, p. 743-763, set. 2016.

SOUSA, M. F. S.; NASCIMENTO, C. M. B.; SOUSA, F. O. S.; LIMA, M. L. L. T.; SILVA, V. L.; RODRIGUES, M. Evolução da oferta de fonoaudiólogos no Sistema Único de Saúde (SUS) e na atenção básica à saúde no Brasil. Rev. CEFAC, São Paulo, v. 19, n. 2, p. 213-220, mar. 2017.

VIÉGAS, L. S. O atendimento à queixa escolar na educação pública baiana. Revista Entreideias: educação, cultura e sociedade, Salvador, v. 5, p. 57-72, 2016.

\section{Como referenciar este artigo}

BOTELHO, B. A.; OLIVEIRA, E. C. Medicalização e a atuação fonoaudiológica frente à queixa escolar. Revista Ibero-Americana de Estudos em Educação, Araraquara, v. 15, n. esp. 5, p. 3056-3073, dez. 2020. e-ISSN: 1982-5587. DOI: https://doi.org/10.21723/riaee.v15iesp5.14574

Submetido em: 10/01/2020

Revisões requeridas em: 25/05/2020

Aprovado em: $30 / 10 / 2020$

Publicado em: 01/12/2020 